\title{
Cyclobenzaprine Hydrochloride
}

National Cancer Institute

\section{Source}

National Cancer Institute. Cyclobenzaprine Hydrochloride. NCI Thesaurus. Code C47465.

A centrally acting muscle relaxant, chemically similar to amitriptyline hydrochloride with antidepressant activity. The exact mechanism of action of cyclobenzaprine hydrochloride has not been fully determined. However, it primarily acts at the brain stem to reduce tonic somatic motor activity, influencing both gamma and alpha motor neurons. This leads to a reduction in muscle spasms. 